\title{
Editorial
}

\section{Work, unemployment and disability: meeting the challenges}

Many of the world economies are currently in the best shape that they have been in decades. In the US, for example, more new jobs have been created within the last 8 years than in any other time period within the century. The inflation rate is lower than it has been since the early 1950 s. Interest rates have been moderate and have not interfered with the growth of the economy which continues to steadily expand at a rate of approx. $3 \%$ per year. An average of approx. 250000300000 new jobs have been created each month with over 8 million jobs in the past 6 years. The recent unemployment rate cited by the US Department of Labor in May 1998 was $4.3 \%$, the lowest since 1957. In the UK, France, Ireland, Germany, and the Netherlands, business is booming with more global business joint ventures and mergers than ever in history.

Although the US economy is expanding at about an annual rate of $3 \%$ or better, in 1998 well above the expected $2.5 \%$ rate, average wages and benefits are actually rising at a slower pace than last year. Most Americans without disabilities are now working, yet pay increases are smaller than ever. How can this be? The answer is productivity. The evidence is now overwhelming that US businesses are continuing to find ways to gain more output from their workers, their machines and their technology, long after the initial wave of downsizing and cost-cutting. Re-designing products to make them cheaper to produce, reengineering processes to take out unnecessary costs - such activities have become a permanent focus of corporate America, imposed by a com- petitive marketplace and encouraged through compensation programs at all levels of the company.

At the same time, as a result of outsourcing and a wave of corporate mergers, more and more economic activity is being shifted out of inefficient firms - or those parts of firms that were inefficient - and into the hands of large, specialized companies that have figured out the best way to do things and can take advantage of the economies of scale. Furthermore, innovations, such as telecommuting, employee leasing, the increase of temporary work agencies, use of the Internet, computer technology, mobile telecommunication devices, part-time work, and self-employment have also contributed to ways of making companies utilize existing personnel in a more efficient way.

Unfortunately, the unemployment level of persons with disabilities has not improved in many countries throughout the world. A number of federal agencies, public policy makers, consumer groups, and professionals have focused significant attention on why the unemployment rate of persons with disabilities remains so high. This unemployment rate in the US has consistently hovered in the $60-70 \%$ area for decades despite increased innovations in rehabilitation and newer laws, such as the Americans with Disabilities Act (P.L. 101-336). Additionally as noted by Hunt et al. (1996), the real economic cost of disability, that is lost production from individuals not at work, has been growing rapidly in recent years. According 
to Chelius et al. (1992) employers have been paying $8 \%$ of payroll for disability-related expanses. Furthermore, innovations, such as assistive technology, health interventions, job coaches, and new training techniques along with progressive laws, designed to ease the entry of persons with disabilities into the competitive work place, have not resulted to date in a noticeable improvement in their level of employment.

One of the more frequently cited polls in recent years in the US which has been done by Louis Harris and Associates (1994) presents a rather discouraging view of the work outcomes achieved by persons with disabilities. In their most recent 1994 poll, Louis Harris and Associates found that two-thirds of Americans with disabilities between the ages of 16 and 64 are not working, with only $20 \%$ working full time and $11 \%$ working part time. They also found that $84 \%$ of unemployed people with disabilities say they want to work, an overwhelming majority that has actually risen by 13 percentage points from an earlier poll taken by Louis Harris in 1986.

In addition, the number of working age people with disabilities who receive Disability Insurance (DI) and Supplemental Security Income (SSI) benefits from the Social Security Administration increased from 4 million in 1985 to 6.3 million in 1994 (General Accounting Office, June 1996). These figures are dramatic indeed because of the enormous expenditures associated with long-term retention on Social Security cash benefits. For example, in 1994 the Social Security Administration reports that the DI Program and SSI Program provided $\$ 52.9$ billion in cash benefits to the 6.3 million working age beneficiaries (General Accounting Office, June 1996). This figure has risen to 8 million Americans receiving 89 billion dollars in FY 1997 (US Bureau of Labor Census, 1997). Yet the Louis Harris Poll indicates that the majority of individuals with disabilities want to work. Considering the substantive advances in assistive technology, rehabilitation technology, and medicine, it is reasonable to ask: What employment strategies have demonstrated success in overcoming the perplexing problem of extremely high unemployment among persons with disabilities?
The development of greatly improved employer accommodations, rehabilitation interventions, and medical treatments play an increasingly large role in the implementation of work supports for workers with disabilities (e.g. Wehman and Kregel, 1998). In the past decade, especially, there has been a significant amount of time, money, and thought gone into studying how these types of accommodations can be utilized to support persons with disabilities and their employers. The key aspect which accommodation, intervention, and treatment all have in common is support. Over the years, a key philosophical change has been the substantial paradigm shift from a clinic or center-based approach of 'fixing/curing' persons with disabilities to instead supporting them with a customized array of resources as designed by the employer, worker, and often rehabilitation provider. These supports can be generated by the business, outside professionals, or the individual and his or her family depending on their need.

With the incredible performance of much of the world economy, it would appear that many of the positive attributes of an improved economy should provide significant employment possibilities for persons with disabilities. One would think that persons with disabilities should have greatly expanded work opportunities and that the unemployment rate for them would be rapidly declining. Unfortunately, this does not appear to be the case. As noted above, the unemployment rate according to the US Bureau of Labor Census (1997) indicates that persons with disabilities are unemployed at a rate still exceeding $60 \%$. Pay is substantially lower for those persons with disabilities, when compared to those without disabilities.

The ability to be employed is important for many reasons. First, working in competitive employment provides an opportunity to receive wages and benefits that may lead to greater independence and mobility in the community at large. Second, as described above, the extraordinary costs associated with maintaining persons with disabilities on Social Security disability rolls are a highly non-productive and inefficient use of human potential in this county that is now reaching an unacceptable level. This high level of entitlement leads to greater federal deficits and ulti- 
mately fosters the incorrect perception among society that people with disabilities are dependent on public support and not capable of active lives that include competitive employment. Third, being productive on a daily basis in a meaningful vocation is critically important to one's self-esteem and dignity. Finally, establishing new friendships and networks of social support in the community is almost always facilitated by having a job within a career path.

Hence the question becomes: What must happen in the workplace to help persons with disabilities capitalize on the extraordinary changes which are transpiring and enjoy the fruits of well paying jobs in competitive employment? What role is there for people with disabilities, especially as the demand for labor becomes incredibly tight? When the Vice Chairman of the Federal Reserve (Rivlin, 12 May 1998) is quoted as saying '....at the rate businesses are hiring, the US economy will soon run out of workers...' there is something terribly wrong or at least highly inefficient with a labor market where large numbers of persons with disabilities remain unemployed. A major theme in this issue will be to present interesting ways to solve this problem. The current issue on International Rehabilitation will try to address some of these challenges and provide some interesting ideas for change.

Paul Wehman

\section{References}

Chelius, J., Galvin, D., Owens, P., 1992. Disability: its more expensive than you think. Bus. Health 11, 78-84.

Hunt, H., Habeck, R., Owens, P., Vandergoot. D., 1996. Disability and work: lessons from the provider sector. In: Mashaw, J.L., Reno, V., Burkhauser, R.V. (Eds.), Disability, Work, Cash Benefits, W.E. Upjohn Institute, Kalamazoo, MI. 